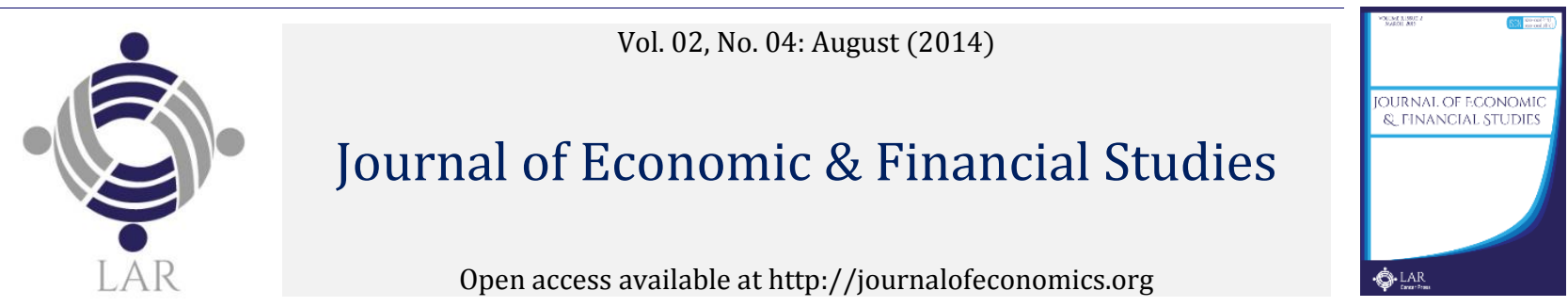

\title{
Is there a case for fuel subsidy removal in Malaysia?
}

\author{
Nor Azam Abdul-Razaka, Russayani Ismailb, Roslan Abdul-Hakimc \\ a Senior Lecturer, School of Economics, Finance \& Banking, Universiti Utara Malaysia, Malaysia. E-mail: azam@uum.edu.my \\ ${ }^{\mathrm{b}}$ Associate Professor, School of Economics, Finance \& Banking, Universiti Utara Malaysia, Malaysia. \\ c Professor, Othman Yeop Abdullah Graduate School of Business, Universiti Utara Malaysia, Malaysia.
}

\section{H I G H L I G H T S:}

1. Fuel subsidy constitutes a huge and growing portion of total subsidy provided in Malaysia.

2. Fuel subsidy reform is costly in terms of the higher prices of non-fuel products.

3. Our analysis suggests that the prices of non-fuel products are expected to rise by $7 \%$ if fuel subsidy is removed.

4. Our analysis suggests that subsidy removal primarily affects the following three categories of goods: food and non-alcoholic beverages; housing, water and electricity; and transportation.

5. Our findings seem to constitute a case against fuel subsidy removal unless measures are taken to mitigate its adverse impact.

\begin{tabular}{ll} 
Article History & ABSTRACT \\
\hline Received: 01-06-2014 & This paper examines the indirect welfare effect of removing fuel subsidy on the Malaysian \\
Accepted: 13-07-2014 & households. The analysis is based on the price-shifting model developed by Coady and \\
Available online: 15-07-2014 & Newhouse (2006) and carried out using the data from the Household Expenditure Survey \\
& $\begin{array}{l}2004-2005 \text { and the input-output table 2004-2005. The analysis yields the following key } \\
\text { results: a) The removal of fuel subsidy is expected to have a relatively huge indirect welfare } \\
\text { effect on the society; b) The indirect welfare effect is expected to be uneven across different }\end{array}$ \\
Keywords: & broad categories of goods (of which the most affected ones are: i) Food and Non-Alcoholic \\
Fuel subsidy; & Beverages, ii) Housing, Water and Electricity; and iii) Transportation); and c) The indirect \\
Indirect welfare effect; & welfare effect is expected to be uniform across different income-based segments of \\
Malaysia; & households. Overall, the findings seem to constitute a case against fuel subsidy removal \\
Subsidy removal. & unless the adverse impact on the three categories of goods is mitigated in some way.
\end{tabular}

JEL Classification:

D63; C81. DOI: http://dx.doi.org/10.18533/jefs.v2i03.54

(C) 2014 The Authors. This is an open access article under the terms of the Creative Commons Attribution License 4.0, which allows use, distribution and reproduction in any medium, provided the original work is properly cited.

\subsection{Introduction}

Fuel subsidy provision has long been a subject of extensive debate among scholars and policymakers. On the one hand, fuel subsidy benefits the society as a whole since its provision raises the standard of living of households through lower input costs as fuel serves as an input to the production of many goods and services. On the other hand, fuel subsidy benefits primarily the higher-income groups in the society since they are the ones who are more likely to consume a larger quantity of fuel and fuel-related goods and services as fuel subsidy usually takes the form of "blanket subsidies" (Global Subsidies Initiative, 2013a). In one study, El-Said and Leigh (2006) reveal that the poorest $30 \%$ of households receive only $13 \%$ of all the subsidies while the richest $10 \%$ of households receive about one-third of the total subsidy. In another study, Baig et al. (2007) report that the bottom $20 \%$ of households receive only $7 \%$ of the total subsidy while the top $20 \%$ receive $43 \%$ of the total subsidy.

In light of these arguments, an analysis of fuel subsidy provision and reform in Malaysia is of special interest since its allocation constitutes a huge and growing portion of the total amount of subsidy provided. During the period 
2000-2008, for example, fuel subsidy constituted an annualized average of about 48.3\% of the total amount of subsidy provided to the public (Ministry of Finance). During the same period, the world fuel price increased from US\$24.54 per barrel to US\$72.49 per barrel while the domestic fuel price rose from RM1.13 per liter to RM2.10 per liter (Ministry of Domestic Trade, Cooperatives and Consumerism). Since the soaring world fuel price has not been matched by a proportionate increase in the domestic fuel price, the "additional" price must have been absorbed by the government through a larger amount of fuel subsidy. If Malaysia continues to behave this way, a steady upward trend in the world fuel price is expected to raise the amount of fuel subsidy, which in turn, might contribute to the ballooning budget deficit.

In anticipation of this problem, the government took a drastic step by raising the domestic fuel price from RM1.92 per liter to RM2.70 per liter (i.e. an increase of about 40\%) in response to a sudden world fuel price hike from US $\$ 61.64$ per barrel to US\$121.00 per barrel (i.e. an increase of about 96\%) in June 2008 (Ministry of Domestic Trade, Cooperatives and Consumerism). In an attempt to curb the deficit further, the government has taken an initiative to phase out subsidies on certain goods and services (including fuel), as stipulated in the Tenth Malaysia Plan (Economic Planning Unit, 2010). In order to carry out the initiative, a special task force named the Performance Management Delivery Unit (PEMANDU) was set up in 2009. Immediately upon its establishment, PEMANDU launched a program called the Subsidy Rationalization Program to provide detailed recommendations on the subsidy rationalization process. Basically, the program recommends that, starting from July 2010, the prices of the subsidized fuel products be raised by RM0.10-RM0.15 per liter every six months during the period 20102014 (PEMANDU, 2010).

Although this policy initiative seems warranted, it is important to note that subsidy rationalization policy is a risky proposition since the resulting higher fuel price is expected to raise the prices of other goods and services, thereby eroding the purchasing power of households. At the same time, since fuel itself is a component of the basket of goods consumed by households, the higher fuel price is expected to contribute directly to the erosion of the purchasing power of households too. Hence, there are two channels in which an increase in the price of fuel affects households: direct and indirect. In the literature on the economics of fuel subsidy reform, the adverse welfare impact originating from the direct (indirect) channel is referred to as the direct (indirect) welfare effect in the literature on the economics of fuel subsidy reform. In this paper, our main interest is on examining the indirect welfare effect of fuel subsidy rationalization in Malaysia (a separate paper is devoted to the investigation of the direct welfare effect). In particular, we seek to measure the magnitude of the indirect welfare (since the direction of the effect is already understood).

The remainder of this paper is organized as follows. Section 2 provides an overview of the literature on the economics of fuel subsidy reform. Section 3 describes the methodology used in this paper. Section 4 presents the findings of this paper. Section 5 recapitulates the analysis and discusses the policy implications which emerge from the findings.

\subsection{Literature review}

There is a huge and burgeoning empirical literature on the economics of fuel subsidy reform [see Global Subsidies Initiative $(2010,2013 \mathrm{~b})$ for an extensive review]. In general, this literature can be divided into two main methodological approaches: partial equilibrium and general equilibrium. As the name implies, the partial equilibrium approach investigates the impact of a fuel subsidy reform on one sector of the economy; in contrast, the general equilibrium approach examines such impact on all sectors of the economy. In view of the premise that a fuel subsidy reform is likely going to have a widespread impact on the economy, the fuel literature has been overwhelmingly dominated by the general equilibrium approach, a partial list of which include Araghi and Bakhordari (2012), Clements et al. (2007), Dartanto (2013), and Jiang and Tan (2013), Lin and Jiang (2011), Liu and Li (2011), and Yusuf and Resosudarmo (2008).

In almost all of these studies, a standard tool of analysis called the computable general equilibrium (CGE) model is employed. Basically, the CGE model specifies and simulates the individual demand-and-supply behavior for all goods and services in the economy. If one takes into account the possible interactions among those goods (e.g. one good is a substitute for another good, one good is a complement to another good, or one good is an input for another good), then one can model the equilibrium price and quantity for each one of them more sophisticatedly. In order to capture the substitute, complement and input-output relationships, the parameters of demand and supply functions need to be calibrated. Once these are done, the economy-wide impact of a fuel subsidy reform is determined by simulating the CGE model in two steps; i.e. before and after the reform (Global Subsidies Initiative, 2010).

Despite its attractive feature, the CGE-based analysis is not without problems. For one thing, it requires a large amount of data, some of which may not be available. For another thing, it requires the need to calibrate the parameters of demand and supply functions, which may not be accurate (Global Subsidies Initiative, 2010). In response to these problems, an alternative (yet simpler) approach to studying the economy-wide impact of a fuel 
subsidy reform, known as the price-shifting model, has been introduced. Basically, the model specifies that each non-fuel good is related to other non-fuel good(s) only through the input-output mechanism implied by the inputoutput table. Then, the economy-wide impact of a fuel subsidy reform is determined by measuring the extent to which the resulting fuel price rise affects the price of each non-fuel product (Coady and Newhouse, 2006).

Within the framework of the price-shifting model, the literature on the economics of fuel subsidy reform can be effectively narrowed down to a relatively few studies such as Andriamihaja and Vecchi (2008), Arze del Granado et al. (2012), Coady and Newhouse (2006), Coady et al. (2006), and El Said and Leigh (2006). In an empirical study on Madagascar, Andriamihaja and Vecchi (2008) found that the indirect welfare effect of fuel subsidy removal was $1.0 \%$. In an empirical study on Ghana, Coady and Newhouse (2006) found that the indirect welfare effect of fuel subsidy removal was 6.7\%. In an empirical study on Gabon, El Said and Leigh (2006) found that the indirect welfare effect of fuel subsidy removal was $4.8 \%$. In addition, Coady et al. (2006) compiled previous empirical studies on a relatively small set of countries (namely, Mali, Sri Lanka, Bolivia, Jordan, and Ghana). They reported that the indirect welfare effects of fuel subsidy removal were 0.8\% (Mali), 1.2\% (Sri Lanka), 3.3\% (Bolivia), and 2.4\% (Jordan). Finally, ArzedelGranado et al. (2012) collected previous empirical studies on 20 developing countries in Africa, Latin America, Asia, and Middle East. They reported that the average indirect welfare effect for these countries was $3.3 \%$.

A glance at all of the above empirical findings indicates that the magnitude of indirect welfare effect ranges between as low as $0.8 \%$ and as high as $6.7 \%$ for those countries. This means that the real income of households is expected to drop by $0.8 \%-6.7 \%$ if fuel subsidy in each of the respective countries is removed. Of course, the question of interest is how much our real income is expected to fall if the Malaysian government decides to remove its fuel subsidy. Since we are interested in the indirect channel of fuel subsidy removal, another question of interest is which non-fuel goods are likely to be affected most by the fuel price rise. Since the income level of households might possibly dictate the composition of the basket of goods that they consume, another question of interest is which income-based segments of households are expected to suffer most from the fuel price rise.

\subsection{Data and Methodology}

As mentioned earlier, indirect welfare effect refers to the impact of a rise in the fuel price through the indirect channel (i.e. through the increase in the prices of other goods). More precisely, it can be defined as the adverse impact of consuming non-fuel products by households when their prices increase in response to the increase in the price of fuel..$^{1}$ Algebraically, indirect welfare effect can be expressed as follows:

(1) $I W E=\sum_{j=1}^{S} w_{j} \Delta q_{j}$

Where $\mathrm{w}_{\mathrm{j}}$ is the budget share of the $\mathrm{j}^{\text {th }}$ good (or service), ${ }^{2} \Delta \mathrm{q}_{\mathrm{j}}$ is the change in the consumer price of the $\mathrm{j}^{\text {th }}$ good (or service), and $\mathrm{S}$ is the number of goods available in the economy.

Assuming that the prices of all non-fuel goods (and services) in the economy are affected by a rise in the fuel price, then

$$
\text { (2) } \Delta q_{j}=f_{j}\left(\Delta p^{\text {oil }}\right)
$$

where $\mathrm{f}_{\mathrm{j}}\left(\Delta \mathrm{p}^{\text {oil }}\right)$ indicates that the change in the consumer price of $\mathrm{j}^{\text {th }}$ non-fuel product is a function of the change in the aggregate producer price of the fuel product, $\Delta \mathrm{p}^{\text {oil }}$. (Note that q is used to denote the consumer price of a good while $p$ the producer price of a good.)

Substituting Eq.(2) into Eq.(1) yields

$$
I W E=\sum_{j=1}^{S} w_{j} f_{j}\left(\Delta p^{\text {oil }}\right)
$$

Eq.(3) states that indirect welfare effect is the sum of the product of the budget share of the $\mathrm{j}^{\text {th }}$ good and the change in the price of the $j^{\text {th }}$ good which is induced by a change in the aggregate fuel price brought about by fuel subsidy removal.

\footnotetext{
${ }^{1}$ By the same token, direct welfare effect can be defined as the adverse impact of directly consuming fuel products (e.g. consuming gasoline for private transportation) when the prices of fuel products increase.

2 The term "budget share of a good (or service)" refers to the ratio of the expenditures on the good (or service) to the expenditures on all goods and services by households.
} 
To calculate the budget shares of all j's goods (i.e. $w_{j}$ for $j=1,2, \ldots, S$ ), we resort to the Household Expenditure Survey (HES) report for Malaysia during the period 2004-2005. The HES report 2004-2005 contains exhaustive monthly data on expenditures and income for a sample of 4,227 selected households in Malaysia during the period 2004-2005. ${ }^{3}$ These data are divided into 12 major categories of goods, ranging from "Food and Non-Alcoholic Beverages" to "Miscellaneous Goods and Services". Dividing the expenditures of all households in the sample on the $\mathrm{j}^{\text {th }}$ good by their total expenditures (i.e. expenditures on the 12 categories of goods) yields the budget share of the $j^{\text {th }}$ good. It should be emphasized that one of the categories, namely, "Housing, Water, Electricity, Gas and Other Fuels", contains expenditures on fuel items. Since our goal is to measure the impact of the fuel price rise on the price of non-fuel goods, the fuel-related expenditures in that category are deliberately excluded, yielding a modified category called "Housing, Water and Electricity".

To calculate the change in the price of the $\mathrm{j}^{\text {th }}$ good induced by a change in the aggregate fuel price [i.e. $\left.\Delta \mathrm{q}_{\mathrm{j}}=\mathrm{f}_{\mathrm{j}}\left(\Delta \mathrm{p}^{\text {oil }}\right)\right]$, we employ the price-shifting model developed by Coady and Newhouse (2006), which involves a mapping fromthe aggregate producer price of fuel to the consumer price of non-fuel products (i.e. from $\Delta \mathrm{p}^{\text {oil }}$ to $\Delta \mathrm{q}_{\mathrm{i}}$ ). In brief, the model assumes that the production technology of the economy is fully described by the input-output (I/0) matrix, which depicts the use of sectoral inputs in the production of sectoral outputs.In the case of Malaysia, the I/O table for 2004-2005 contains 120 sectors, ranging from "Paddy" to "Other Private Services". From this I/O table, the mechanism through which a change in the input price (i.e. $\Delta$ p $^{\text {oil) }}$ is passed onto the output price (i.e. $\Delta \mathrm{q}_{\mathrm{j}}$ ) is determined (see the Appendix for details). Once the mechanism has been set and applied, we obtain the percentage increases in the consumer prices of 120 goods and services.

Since the budget share data are available for merely 12 goods and services, there is a need to convert (or aggregate) the $1 \times 120$ vector of the changes in the consumer prices of goods and into the $1 \times 12$ vector of consumer prices. The aggregation process is accomplished by matching the codes for the individual expenditure items in the HES report to the codes for the individual expenditure items in the I/O table using a converter furnished by the Department of Statistics. ${ }^{4}$ Once the aggregation is done, indirect welfare effect can be calculated by multiplying the budget share of each of the 12 goods and services by the percentage increase in the corresponding price of each of the 12 goods and services.

It remains to specify the change in the aggregate price of fuel products, $\Delta \mathrm{p}^{\text {oil }}$, which is defined as the weighted sum of the change in the prices of all fuel products:

(4) $\Delta p^{\text {oil }}=\sum_{j=1}^{J} \delta_{j} \Delta p_{j}^{o i l}$

Where, $\Delta p_{j}^{\text {oil }}$ is the change in the price of the $\mathrm{j}^{\text {th }}$ fuel product and $\delta_{\mathrm{j}}$ is its quantity share. (This term should not be confused with the term "budget share" which was defined earlier. $)^{5}$

The introductory section implies that there are three major fuel products consumed by households in Malaysia: RON97, RON95 and diesel. Of the three, RON95 captures 56.3\% of the quantity share, diesel 35\%, and RON97 8.7\% (i.e. $\delta_{1}=0.563, \delta_{2}=0.35$, and $\delta_{3}=0.087$ ). ${ }^{6}$ Given their current pre- and post-subsidy prices, the price is expected to increase by $54.1 \%$ for RON95, $49.1 \%$ for diesel, and $28.7 \%$ for RON97 should the government remove the entire subsidy for each fuel product (i.e. $\Delta \mathrm{p}_{1}=0.541, \Delta \mathrm{p}_{2}=0.491$, and $\Delta \mathrm{p}_{3}=0.287$ ). ${ }^{7}$ Substituting all of these figures into Eq. (4) yields the value of $0.5014 .{ }^{8}$ Hence, the aggregate price of fuel is expected to increase by $50.14 \%$ if the subsidy on each of the above fuel products is removed.

\subsection{Empirical results}

\footnotetext{
${ }^{3}$ To begin with, the HES report 2004-2005 contains the data on expenditures and income for slightly more than 12,000 households in Malaysia. For technical reason, however, the data for merely one-third of the sample (i.e. 4,227 households) are made available to the authors.

${ }^{4}$ The expenditure items in the HES report are documented using the Consumer Price Index (CPI) code while the expenditure items in the I/O table are documented using the Malaysian Standard Industrial Classification (MSIC) code. What the converter does is essentially match these two different codes.

${ }^{5}$ The term "quantity share of a fuel product" refers to the ratio of the quantity of a particularfuel product to thequantity of all fuel products consumed by households.

${ }^{6}$ The data are extracted from the figures provided by the Ministry of Domestic Trade, Cooperative and Consumerism.

7 As of December 2010, RON97 was sold at RM2.30/liter while its average market price was RM2.96/liter; hence, the government provided a subsidy of $22.3 \%$. By the same token, RON95 was sold at RM1.90/liter while its average market price was RM2.93/liter; thus, the subsidy was $35.26 \%$. Finally, diesel was sold at RM1.80/liter while its average market price was RM2.68/liter; hence, the subsidy was $32.84 \%$.
}

${ }^{8} \Delta p^{\text {oil }}=\sum_{j=1}^{3} \delta_{j} \Delta p_{j}^{\text {oil }}=(0.563 \times 0.541)+(0.35 \times 0.491)+(0.087 \times 0.287)=0.5014$. 
Table 1 shows basic statistics for a sample of 4,227 households from the HES report 2004-2005. The average household income is RM2954, the average household expenditure is RM1906, and the average fuel consumption is RM185. This means that, on average, household fuel consumption constitutes about $9.7 \%$ of its total expenditure, and $6.3 \%$ of its income. When the sample is divided into five groups based on the household income level, we find that the average household income is RM749 for the bottom 20\% group and RM7339 for the top 20\% group. This means that the income ratio of the richest $20 \%$ group to the poorest $20 \%$ group is 9.8 to 1 . In terms of total household expenditure, we find that the average expenditure is RM679 for the bottom 20\% group and RM3850 for the top $20 \%$ group. This gives the expenditure ratio of the richest $20 \%$ group to the poorest $20 \%$ group is 5.7 to 1 . In terms of fuel consumption, we find that the average consumption is RM44 for the bottom 20\% group and RM305 for the top $20 \%$ group. This gives the fuel consumption ratio of the richest $20 \%$ group to the poorest $20 \%$ group of 7 to 1 . This last piece of findings is consistent with that found by Arze del Granado et al.(2007), who note that, for a sample of selected countries, the top 20\% group receives about 6 times more in subsidies than the bottom $20 \%$ group (see Table 3 in their paper).

The basic statistics indicate that the higher income groups consume more fuel than the lower income groups (see the last column). To the extent that this finding means that the benefits of fuel subsidy accrue more to the higher income groups than the lower income groups, it seems that removing fuel subsidy is justifiable on equity ground. However, it is important to note that since fuel serves as an input to the production of many goods and services, a rise in the price of fuel brought about by its subsidy removal is expected to have a multiplier or spiral effect on the economy. This means that the welfare impact of removing fuel subsidy is far more complicated than a rudimentary analysis might suggest. Using the sample of 4,227 households, we calculate the indirect welfare effect on the 12 categories of goods of the fuel price rise due to subsidy removal. The calculation can be performed in two steps: a) for each category of goods, its price change is multiplied by the household budget share; and b) the product is summed over the 12 categories of goods. Table 2 shows the budget shares, the price changes (called the price effects), and the product of the two (called the expenditure effects) for the 12 categories of goods. Adding the expenditure effects for all of the 12 categories yields the indirect welfare effect, which is 6.97. This value means that the real income of households is expected to fall by about $7 \%$ if the prices of non-fuel products rise due to the fuel price rise by $50.14 \%$.

\begin{tabular}{|lcccccc|}
\hline \multicolumn{1}{c}{ Income } \\
$\begin{array}{c}\text { groups } \\
\text { (Quintile) }\end{array}$ & $\begin{array}{c}\text { Average } \\
\text { Income } \\
\text { (RM) }\end{array}$ & $\begin{array}{c}\text { Ratio of } \\
\text { Average } \\
\text { Income to the } \\
\text { poorest }\end{array}$ & $\begin{array}{c}\text { Average } \\
\text { Expenditure } \\
\text { (RM) }\end{array}$ & $\begin{array}{c}\text { Ratio of Average } \\
\text { Expenditure to } \\
\text { the poorest } \\
\text { quintile (Q5) }\end{array}$ & $\begin{array}{c}\text { Average fuel } \\
\text { consumption } \\
\text { per month } \\
\text { (RM) }\end{array}$ & $\begin{array}{c}\text { Ratio of } \\
\text { Average fuel } \\
\text { Consumption } \\
\text { to the poorest } \\
\text { quintile (Q5) }\end{array}$ \\
\hline Q1 (Richest) & 7338.91 & 9.80 & $3,849.80$ & 5.67 & 305.47 & 7.01 \\
Q2 & 3148.35 & 4.20 & $2,136.82$ & 3.15 & 200.98 & 4.61 \\
Q3 & 2119.15 & 2.83 & $1,674.95$ & 2.47 & 128.96 & 2.96 \\
Q4 & 1410.26 & 1.88 & $1,182.77$ & 1.74 & 87.81 & 2.02 \\
Q5 (Poorest) & 749.23 & 1.00 & 678.70 & 1.00 & 43.56 & 1.00 \\
Total & 2953.57 & 3.94 & 1905.85 & 2.81 & 185.14 & 4.25 \\
\hline
\end{tabular}

Compared to the findings of the previous studies (see Section 2), the magnitude of indirect welfare effect in our study is very large (in fact, our figure is the largest). In our case, this huge figure is contributed by three broad categories of goods: "Housing, Water and Electricity"; "Transportation"; and "Food and Non-Alcoholic Beverages". Together, these three categories of goods contribute almost $80 \%$ of the indirect welfare effect (see the last column), and this means that the three categories of goods are expected to experience the largest price hike following the fuel subsidy removal.

Table 02: Indirect welfare effect of removing fuel subsidies in Malaysia

\begin{tabular}{|c|c|c|c|c|}
\hline \multirow{2}{*}{ Categories of Goods } & Budget Shares (\%) & Price Effects (\%) & $\begin{array}{l}\text { Expenditure } \\
\text { Effects (\%) }\end{array}$ & $\begin{array}{l}\text { Total Impact } \\
\qquad(\%)\end{array}$ \\
\hline & 1 & 2 & $(1 \times 2) / 100$ & \\
\hline 01-Food and Non-Alcoholic Beverages & 20.66 & 7.92 & 1.64 & 23.48 \\
\hline 02-Alcoholic Beverages and Tobacco & 1.92 & 0.89 & 0.02 & 0.24 \\
\hline 03-Clothing and Footwear & 3.44 & 3.14 & 0.11 & 1.55 \\
\hline 04-Housing, Water and Electricity & 20.96 & 9.22 & 1.93 & 27.73 \\
\hline $\begin{array}{l}\text { 05-Furnishing, Household Equipment and } \\
\text { Routine }\end{array}$ & 4.59 & 3.31 & 0.15 & 2.18 \\
\hline 06-Health & 1.41 & 1.37 & 0.02 & 0.28 \\
\hline 07-Transport & 15.90 & 11.63 & 1.85 & 26.53 \\
\hline
\end{tabular}




\begin{tabular}{lcccc} 
08-Communication & 5.15 & 0.46 & 0.02 & 0.34 \\
09-Recreation Services and Culture & 4.45 & 8.01 & 0.36 & 5.12 \\
10-Education & 1.86 & 1.25 & 0.02 & 0.33 \\
11-Restaurants and Hotels & 11.33 & 3.28 & 0.37 & 5.33 \\
12-Miscellaneous Goods and Services & 8.33 & 5.76 & 0.48 & 6.89 \\
Total & 100.0 & - & 6.97 & 100.00 \\
\hline
\end{tabular}

The large contribution of the above three categories of goods, in turn, is contributed by a combination of their large budget shares and price effects. In terms of the budget shares, our analysis shows that "Housing, Water and Electricity" ranks the first (21.0\%), followed by "Food and Non-Alcoholic Beverages" (20.7\%), and "Transportation" (15.9\%). Interms of the price effects, our analysis shows that "Transportation" records the highest price rise (11.7\%), followed by "Housing, Water and Electricity" (9.2\%), and "Food and Non-Alcoholic Beverages" (7.9\%). (Note that "Recreation Services and Culture" also records a high price increase, which is 8\%.)

These results can be compared to those in the previous studies. In Coady and Newhouse (2006), goods and services (or sectors) are divided into nine categories which differ from our classification. Of these, the major ones are "Agriculture" (44.8\%), "Manufacturing" (19.4\%), and "Transport" (11.9\%) (see Table 11.3 in their paper). In Andriamihaja and Vecchi (2008), goods and services are divided into 30 sectors which also differ from our classification. Of these, the major ones are "Food" (63.4\%), "Textile" (7.2\%), and "Fats" (6.9\%) (see Table 11.3 in their paper). In Arze del Granado et al. (2012), goods and services are divided into three categories only: "Food", "Transport", and "Others". Of these, "Food" captures 39.6\% of indirect welfare effect while "Transport" captures a mere $10 \%$ of indirect welfare effect (see Table 10 in their paper).

Quite often the types and quantities of goods that households purchase depend on their income levels, thereby possibly altering the composition and magnitude of the household budget shares. Accordingly, the magnitude of indirect welfare effect might vary according to the income levels of households. To accommodate this line of thought, we divide our sample of households into five income groups (or quintiles) and repeat the previous analysis. As shown in Table 3, however, we find that the magnitude of indirect welfare effect is uniform across the five quintiles with the value of 7\%. It is interesting to note that this pattern of finding is broadly consistent with that in the previous studies by Coady and Newhouse (2006)(see Table 11.2 in their paper), Andiramihaja and Vecchi (2008)(see Table 11.4 in their paper), and ArzedelGranado et al. (2012)(see Table 2 in their paper).

The source of this uniformity has to do with the fact that the same three categories of goods (as a group) consistently dominate the budget shares of households regardless of their income levels. Across the five quintiles, the budget shares of households range from a) $19.9 \%$ to $26.0 \%$ for "Housing, Water and Electricity"; b) $15.1 \%$ to $32.6 \%$ for "Food and Non-Alcoholic Beverages"; and c) 7.9\% to $18.5 \%$ for "Transportation".

Nonetheless, it is interesting to note that the dominance of the household budget shares by each category of goods does vary by the household income levels. A comparison of the budget shares across quintiles reveals two intriguing patterns: a) the magnitude of the budget shares decreases with income levels for "Housing, Water and Electricity" and "Food and Non-Alcoholic Beverages"; and b) the magnitude of the budget shares increases with income level for "Transportation".

Coupled with the price effects (which are uniform across the quintiles), we will be able to determine the relative contribution of the three categories of goods to indirect welfare effect by the levels of household income. A comparison of the expenditure effects across quintiles reveals three interesting patterns: a) the contribution of "Food and Non-Alcoholic Beverages" to indirect welfare effect decreases with income levels; b) the contribution of "Transportation" to indirect welfare effect increases with income levels; and c) the contribution of "Housing, Water and Electricity" to indirect welfare effect decreases with income levels up to a certain point (and stabilizes beyond this point).

\subsection{Conclusion and Policy Implications}

In this paper, we study the indirect welfare effect of removing fuel subsidy in Malaysia on households. By indirect welfare effect, we mean the increase in the prices of non-fuel goods and services in the economy brought about by the increase in the price of fuel due to the removal of fuel subsidy. The analysis is based on the price-shifting model developed by Coady and Newhouse (2006) and the Malaysian data from the Input-Output Table 2004-2005 and Household Expenditure Survey report 2004-2005 using a sample of 4,227 households.

We begin the analysis by looking at the income, the total expenditure, and the fuel expenditure for a sample of 4,227 selected households in Malaysia. We find that the higher-income households consume much more fuel than the lower-income households. This preliminary finding indicates that the richer section of the society benefits more 
from the fuel subsidy than the poor one. Inasmuch this outcome defeats the purpose of the subsidy policy, subsidy removal seems justifiable.

We continue the analysis by studying the indirect welfare effect of removing fuel subsidy on households in general. Given the data on the prices and quantities of petroleum goods, the removal of subsidy is expected to raise the fuel price by approximately 50\%. Employing the price-shifting model, our analysis yields three main results. First, the magnitude of indirect welfare effect of fuel subsidy removal in Malaysia is expected to be about 7\%. Compared to the findings of the previous studies, indirect welfare effect in Malaysia is very strong. 


\begin{tabular}{|c|c|c|c|c|c|c|c|c|c|c|c|c|c|}
\hline \multicolumn{14}{|c|}{ Table 03: Indirect welfare effect of removing fuel subsidies by income groups in Malaysia } \\
\hline GOODS & 01 & 02 & 03 & 04 & 05 & 06 & 07 & 08 & 09 & 10 & 11 & 12 & TOTAL \\
\hline \multicolumn{14}{|c|}{ First Quintile (Richest/Top20\%) } \\
\hline Budget Shares & 15.1 & 1.59 & 3.09 & 19.87 & 5.41 & 1.62 & 18.53 & 5.88 & 5.58 & 2.37 & 11.07 & 9.9 & 100 \\
\hline Price Effects & 7.919 & 0.889 & 3.135 & 9.221 & 3.312 & 1.367 & 11.630 & 0.459 & 8.013 & 1.249 & 3.279 & 5.761 & - \\
\hline Impact on & 1.196 & 0.014 & 0.097 & 1.832 & 0.179 & 0.022 & 2.155 & 0.027 & 0.447 & 0.030 & 0.363 & 0.570 & 6.93 \\
\hline Percent of Total & 17.25 & 0.20 & 1.40 & 26.43 & 2.58 & 0.32 & 31.08 & 0.39 & 6.45 & 0.43 & 5.24 & 8.23 & 99.99 \\
\hline \multicolumn{14}{|c|}{ Second Quintile } \\
\hline Budget Shares & 20.69 & 1.77 & 3.52 & 20.83 & 4.49 & 1.5 & 15.75 & 5.29 & 4.32 & 1.89 & 12.08 & 7.88 & 100 \\
\hline Price Effects & 7.919 & 0.889 & 3.135 & 9.221 & 3.312 & 1.367 & 11.630 & 0.459 & 8.013 & 1.249 & 3.279 & 5.761 & - \\
\hline Impact on & 1.638 & 0.016 & 0.110 & 1.921 & 0.149 & 0.021 & 1.832 & 0.024 & 0.346 & 0.024 & 0.396 & 0.454 & 6.93 \\
\hline Percent of Total & 23.64 & 0.23 & 1.59 & 27.72 & 2.15 & 0.30 & 26.43 & 0.35 & 5.00 & 0.34 & 5.72 & 6.55 & 100.01 \\
\hline \multicolumn{14}{|c|}{ Third Quintile } \\
\hline Budget Shares & 23.57 & 2.36 & 3.75 & 20.65 & 3.93 & 1.18 & 15.93 & 4.84 & 3.98 & 1.45 & 11.14 & 7.23 & 100 \\
\hline Price Effects & 7.919 & 0.889 & 3.135 & 9.221 & 3.312 & 1.367 & 11.630 & 0.459 & 8.013 & 1.249 & 3.279 & 5.761 & - \\
\hline Impact on & 1.867 & 0.021 & 0.118 & 1.904 & 0.130 & 0.016 & 1.853 & 0.022 & 0.319 & 0.018 & 0.365 & 0.417 & 7.05 \\
\hline Percent of Total & 26.48 & 0.30 & 1.67 & 27.01 & 1.85 & 0.23 & 26.28 & 0.32 & 4.52 & 0.26 & 5.18 & 5.91 & 100.01 \\
\hline \multicolumn{14}{|c|}{ Fourth Quintile } \\
\hline Budget Shares & 27.79 & 2.32 & 3.87 & 22.28 & 3.71 & 1.1 & 12.17 & 4.17 & 2.93 & 1.15 & 11.26 & 7.26 & 100 \\
\hline Price Effects & 7.919 & 0.889 & 3.135 & 9.221 & 3.312 & 1.367 & 11.630 & 0.459 & 8.013 & 1.249 & 3.279 & 5.761 & - \\
\hline Impact on & 2.201 & 0.021 & 0.121 & 2.055 & 0.123 & 0.015 & 1.415 & 0.019 & 0.235 & 0.014 & 0.369 & 0.418 & 7.01 \\
\hline Percent of Total & 31.41 & 0.29 & 1.73 & 29.32 & 1.75 & 0.21 & 20.20 & 0.27 & 3.35 & 0.20 & 5.27 & 5.97 & 100.00 \\
\hline \multicolumn{14}{|c|}{ Fifth Quintile (Poorest/Bottom 20\%) } \\
\hline Budget Shares & 32.56 & 2.46 & 3.68 & 25.98 & 3.39 & 1.08 & 7.88 & 3.06 & 2.26 & 1.14 & 11.05 & 5.45 & 100 \\
\hline Price Effects & 7.919 & 0.889 & 3.135 & 9.221 & 3.312 & 1.367 & 11.630 & 0.459 & 8.013 & 1.249 & 3.279 & 5.761 & - \\
\hline Impact on & 2.579 & 0.022 & 0.115 & 2.396 & 0.112 & 0.015 & 0.916 & 0.014 & 0.181 & 0.014 & 0.362 & 0.314 & 7.04 \\
\hline $\begin{array}{l}\text { Percent of Total } \\
\text { Impact }\end{array}$ & 36.62 & 0.31 & 1.64 & 34.02 & 1.59 & 0.21 & 13.02 & 0.20 & 2.57 & 0.20 & 5.15 & 4.46 & 100.00 \\
\hline
\end{tabular}


This suggests that subsidy removal is expected to severely affect the Malaysian households through increases in the prices of non-fuel goods and services. Second, the indirect welfare effect is dominated by three broad categories of goods: "Food and Non-Alcoholic Beverages", "Housing, Water and Electricity", and "Transportation". Together, they contribute about $80 \%$ of indirect welfare effect of subsidy removal. This means that subsidy removal is expected to adversely affect the three categories of goods most. Third, the indirect welfare effect is uniform across households of different income groups. This means that subsidy removal is expected to adversely affect the low-, middle-, and high-income groups equally.

Of the three findings, the first two seem to suggest the same policy direction and the third one a different one. In particular, the third finding implies that the impact of fuel subsidy removal is likely to be neutral across households with diverse income groups. Accordingly, the policy is unlikely to contribute to widening income inequality; hence, there seems to be a case for fuel subsidy removal. Unlike the third finding, the first one suggests that the impact of fuel subsidy removal is likely to be serious, and the second one indicates that the burden of fuel subsidy removal is likely to fall on three broad categories of goods more than others. Taken together, these two sets of finding seem to constitute a case against the fuel subsidy removal unless of course the adverse impact on the three broad categories of goods is mitigated in some way.

In order to come up with appropriate mitigating measures, it is useful to understand the nature of the goods in question, namely "Food and Non-Alcoholic Beverages", "Housing, Water and Electricity", and "Transportation". One common feature of these goods is that all of them are necessity goods. Therefore, the demand for each of them is expected to be highly inelastic. This implies that the decrease in the supply of each good (i.e. the leftward shift in the supply curve) brought about by a fuel price rise is expected to lead to a huge increase in the price of each of them.

For concreteness, consider food. Inasmuch as the inelastic feature of food is fixed and on the demand side of the food market, the burden of change is on the supply side of the food market. Question: What is the nature of the supply side of the food market in Malaysia? According to the supply theory, the non-price determinants of supply are the price of inputs, the number of producers, the level of technology, etc. As far as fuel serves as an input into the production of food, a rise in the fuel price is expected to affect the food price. However, a consideration is that how much fuel accounts for the production of food. Although the answer varies according to the type of food, we suspect that the cost share of fuel is quite negligible. Hence, it is reasonable to conjecture that the relatively large decrease in the food supply is contributed by other supply determinants, of which one likely reason is the number of producers.

If we take fish, for instance, we observe that there are a relatively large number of fishermen in the country. However, the price of fish is relatively high. Casual observations tell us that, despite the presence of a relatively large number of fishermen, the number of wholesalers is relatively few. Hence, they have a substantial market power to increase the fish price in response to the rise in fuel price. One policy option to face the powerful wholesalers is by implementing price regulation. However, its success requires a strict and consistent enforcement by the government since price regulation per se in unlikely to be adequate to deal with this kind of market imperfection. (As of now, "price regulation" on fish takes the form of moral suasion and occasional visits made by authorities to the fish markets to ensure that price tags on fish sold are in place.)

Another policy option to confront the powerful wholesalers is by lessening their market power. One way to do this is by encouraging new entries into the wholesale fish business. Quite often, a new entrant into an otherwise monopolistic (or oligopolistic) industry is likely to face price war by established firms. Again, there is a case for a government's intervention in promoting a healthy competitive environment among the wholesalers. Another way to do this is by introducing cooperatives which act as wholesalers for distributing fishes to retailers. Unlike private new entrants, cooperatives are less likely going to face price war because they are owned by many fishermen. However, managing cooperatives might pose a challenge for their survival. Once again, there is a case for the government's intervention in maintaining the cooperatives. In either case, the additional number of producers (i.e. wholesalers in this case) might undermine the market power of individual wholesalers.

Although our discussion was confined to food products, it can be easily generalized to housing and transportation goods. In the case of housing, we also observe that the producers have substantial market power. In order to fight this kind of market imperfection, the government might be called for to implement price regulation. (Lessening market power through new entries or cooperatives may be inappropriate in this case due to the need to raise huge capital.) In this case too, a strict and consistent enforcement by the government is required. In the case of transportation, it is very clear that the producers have substantial market power since the domestic car industry is dominated by our national car producers. In this case, however, the powerful producers are owned by the government. Accordingly, the government has a better control over the car prices in the event of fuel subsidy removal. In a nutshell, active government interventions are needed in the markets characterized by the presence of market power on the part of sellers should the government choose to pursue its subsidy removal policy. 


\section{References}

Andriamihaja, N. and Vecchi, G. 2008. Evaluation of the welfare impact of higher energy prices in Madagascar, in: Go, D. and Page, J. (Eds.), Africa at a turning point? Growth, Aid and External Shocks.Washington: World Bank.

Araghi, M. and Bakhordari, S.2012. An evaluation of the welfare effects of reducing energy subsides in Iran. Energy Policy. 47(8): 398-404. http://dx.doi.org/10.1016/j.enpol.2012.05.007

ArzedelGranado, J. Coady, D. and Gillingham, R. 2012. The unequal benefits of fuel subsidies: A review of evidence for developing countries. World Development. 40(11): 2234-2248. http://dx.doi.org/10.1016/j.worlddev.2012.05.005

Baig, T., Mati, A., Cady, D. and Ntamatungiro, J., 2007. Domestic petroleum product prices and subsidies: Recent developments and reform strategies. Washington D.C.: International Monetary Fund.

Clements, B. Gupta, J. and Jung, S. 2007. Real and distributive effects of petroleum price liberalization: The case of Indonesia. Developing Economies. 45(2): 220-237. http://dx.doi.org/10.1111/j.1746-1049.2007.00040.x

Coady, D., El-Said, M., Gillingham, R., Kpodar, K., Medas, P., and Newhouse D. 2006. The magnitude and distribution of fuel subsidies: Evidence from Bolivia, Ghana, Jordan, Mali and Sri Lanka. IMF Working Paper. 06(247), Washington D.C: International Monetary Fund.

Coady, D. and Newhouse, D. 2006. Ghana: Evaluating the fiscal and social costs of increases in domestic fuel prices, in: Coudouel, A., Dani, A. andPaternostro, S. (Eds.), Poverty and Social Analysis of Reforms: Lessons and Examples from Implementation. Washington: World Bank.

Dartanto, T. 2013. Reducing fuel subsidies and the implication on fiscal balance and poverty in Indonesia: A simulation analysis.Energy Policy. 58(July): 117-134. http://dx.doi.org/10.1016/j.enpol.2013.02.040

Economic Planning Unit, 2010. Tenth Malaysia Plan 2011-2015, Malaysia: Economic Planning Unit

El Said, M. and Leigh, D. 2006. Fuel price subsidies in Gabon: Fiscal cost and distributional impact. IMF Working Paper, 06(243). Washington D.C: International Monetary Fund.

Global Subsidies Initiative, 2010. The effects of fossil-fuel subsidy reform: A review of modeling and empirical studies. Geneva: International Institute for Sustainable Development.

Global Subsidies Initiative, 2013a.A citizen's guide to energy subsidies in Malaysia.

Global Subsidies Initiative, 2013b.A guidebook to fossil-fuel subsidy reform for policy-makers in Southeast Asia.

Jiang, Z. and Tan, J. 2013. How the removal of energy subsidy affects general price in China: A study based on inputoutput model. Energy Policy. 60(12): 599-606. http://dx.doi.org/10.1016/j.enpol.2013.08.059

Lin, B. and Jiang, Z. 2011. Estimates of energy subsidies in China and impact of energy subsidy reform.Energy Economics. 33(2): 273-283. http://dx.doi.org/10.1016/j.eneco.2010.07.005

Liu, W. and Li, H. 2011.Improving energy consumption structure: A comprehensive assessment of fossil energy subsidies reform in China.Energy Policy. 39(7): 4134-4143. http://dx.doi.org/10.1016/j.enpol.2011.04.013

Ministry of Domestic Trade, Cooperation and Consumerism.Petroleum Information 2010. Malaysia. Retrieved fromhttp://www.kpdnkk.gov.my/web/guest/index

Ministry of Finance.Economic Report 2010/2011 and others. Malaysia. Retrieved fromhttp://www.treasury.gov.my/index.php?option=com_content\&view=category\&id=73\&Itemid=174\&lan $\mathrm{g}=\mathrm{en}$

PEMANDU, 2010. Opening presentation: Subsidy rationalization lab open day. Kuala Lumpur: Performance Management and Delivery Unit. Retrieved fromhttp://www.slideshare.net/Adamloh/subsidy-rationalizationlab-by-day

Yusuf, A. and Resosudarmo, B. 2008.Mitigating the distributional impact of fuel pricing reform: the Indonesian experience.ASEAN Economic Bulletin. 25(1): 32-47. http://dx.doi.org/10.1355/AE25-1D

\section{Appendix: 01}

The price-shifting model assumes that the production technology of the economy can be completely described by the input-output (I-0) matrix, which depicts the use of sectoral inputs in the production of sectoral outputs. In the case of Malaysia, the I-O table for 2004-2005 contains 120 sectors, ranging from paddy to other private services. Hence, the I-O coefficient matrix associated with the I-O table is of dimension $120 \times 120$. This I-O coefficient matrix is denoted by A as follows:

(A1) $\mathbf{A}=\left[\begin{array}{cccc}a_{11} & a_{12} & \ldots & a_{1 S} \\ a_{21} & a_{22} & \ldots & a_{2 S} \\ \ldots \ldots \ldots \ldots \ldots \ldots \ldots \ldots . . \\ \ldots \ldots \ldots \ldots \ldots \ldots & \ldots \ldots \ldots & \ldots \\ a_{S 1} & a_{S 2} & \ldots & a_{S S}\end{array}\right]$ 
where $a_{i j}(i, j=1,2, \ldots, S)$ is the cost of the $i^{\text {th }}$ input per unitary value of the $j^{\text {th }}$ output (units of output are defined in such a way that they have a user price of unity) or, more precisely, a change in the cost of producing one unit of $j^{\text {th }}$ output due to a unit change in the price of $\mathrm{i}^{\text {th }}$ input.

In order to determine the mechanism through which changes in input prices are passed onto output prices, it is assumed that all of the existing sectors (i.e. $S=120$ ) can be grouped into three broad sectors: traded, cost-push, and controlled. As the name implies, the traded sectors are sectors which compete with internationally traded goods; therefore, higher input costs cannot be fully passed onto output prices. In brief, the cost-push sectors are nontraded sectors (such as most government services, construction, public utilities, trade and transportation, and retail and wholesale trade); hence, higher input costs are pushed fully onto output prices. Finally, the controlled sectors are sectors where output prices are controlled by the government; thus, higher input costs cannot be fully passed onto output prices.

Given the above three broad sectors, the pricing scheme for each of them (in terms of how changes in input prices are passed onto output prices) can be expressed as follows:

$$
\begin{aligned}
\mathbf{q}^{c p} & =\mathbf{p}^{c p}+\mathbf{t}^{c p} \quad[\text { cost-push }] \\
\mathbf{q}^{t s} & =\mathbf{p}^{w}+\mathbf{t}^{t s} \quad[\text { traded }] \\
\mathbf{q}^{c s} & \left.=\mathbf{p}^{*} \text { [controlled }\right]
\end{aligned}
$$

where $\mathbf{q}$ is the $1 \times S$ vector of consumer prices, $\mathbf{p}$ is the $1 \times S$ vector of producer prices (net of sales taxes and/or tariffs), $\mathbf{q}^{\mathrm{cp}}$ is the price paid by consumers in the cost-push sectors, $\mathbf{p}^{\mathrm{cp}}$ is the price set by producers in the cost-push sectors, $\mathbf{t}^{\mathrm{c}}$ is the sales or excise taxes imposed by the government in the cost-push sectors, $\mathbf{q}^{\text {ts }}$ is the price paid by consumers in the traded sectors, $\mathbf{p}^{\mathrm{w}}$ is the world prices, $\mathrm{t}^{\mathrm{ts}}$ is the trade taxes, $\mathbf{q}^{\mathrm{cs}}$ is the price paid by consumers in the controlled sectors, and $\mathbf{p}^{*}$ is the price controls set by the government.

Given these pricing schemes, it can be easily shown that price changes in each of these sectors are given by

$$
\begin{aligned}
& \text { (A5) } \Delta \mathbf{q}^{c p}=\Delta \mathbf{p}^{c p}+\Delta \mathbf{t}^{c p} \quad \text { [cost-push] } \\
& \text { (A6) } \Delta \mathbf{q}^{t s}=\Delta \mathbf{p}^{w}+\Delta \mathbf{t}^{t s}[\text { traded }] \\
& \text { (A7) } \Delta \mathbf{q}^{c s}=\Delta \mathbf{p}^{*}[\text { controlled }]
\end{aligned}
$$

Of all the right-hand side variables, four of them (i.e. $\Delta \mathbf{p}^{\mathrm{w}}, \Delta \mathbf{p}^{*}, \Delta \mathbf{t}^{\mathrm{cp}}$, and $\Delta \mathbf{t}^{\mathrm{ts}}$ ) are exogenous while $\Delta \mathrm{p}^{\mathrm{cp}}$ is endogenous. The endogeneity of this final variable is due to the fact that the producer prices of goods depend on all factor prices of intermediate goods:

$$
\Delta \mathbf{p}^{c p}=\Delta \mathbf{p}^{c p}(\mathbf{q}) \Rightarrow \Delta \mathbf{q}^{c p}=\Delta \mathbf{p}^{c p}(\mathbf{q})+\Delta \mathbf{t}^{c p}
$$

whereq is a vector of intermediate goods included in the I-O table. (Andriamihaja and Vecchi (2008) claim that $\Delta \mathbf{p}^{\mathrm{cp}}$ is a function of a price vector of intermediate goods not included in the I-O table as well. Since the data for this price vector are not available, they are disregarded upfront.)

It is important to note that, although $\mathbf{q}$ is a vector of consumer prices, it is also a vector of input prices for certain sectors. Then, how do changes in q pass on to final prices? To get around this problem, Coady and Newhouse (2006) assume that each of the composite commodities is made up of a certain proportion of cost-push, traded and controlled sectors. To fix ideas, let $\alpha, \beta$ and $\gamma$ denote the proportion of cost-push, traded and controlled sector, respectively. Then each of them is a positive fraction and they add up to unity:

$$
0 \leq \alpha_{j}, \beta_{j}, \gamma_{j} \leq 1 ; \alpha_{j}+\beta_{j}+\gamma_{j}=1 \quad(j=1,2, \ldots, 120)
$$

To illustrate, consider the $28^{\text {th }}$ sector in our I-O table (i.e. the soft drink sector). In order to produce soft drink, suppose its producers buy 30\% of inputs from the producers of the cost-push sector, $30 \%$ of inputs from the producers of the traded sector, and $40 \%$ of inputs from the producers of the controlled sector. Then, $\alpha_{28}=\beta_{28}=$ 0.30 and $\gamma_{28}=0.40$. This means that the change in the price of the soft drink commodity can be expressed as a linear combination of the three broad sectors. In general, the change in the price of the $\mathrm{j}^{\text {th }}$ commodity can be expressed as a linear combination of the three broad sectors: 
(A10)

$$
\Delta p_{j}^{c p}(\mathbf{q})=\sum_{i=1}^{S} \alpha_{i} a_{i j} \Delta q_{j}^{c p}+\sum_{i=1}^{S} \beta_{i} a_{i j} \Delta q_{j}^{t s}+\sum_{i=1}^{S} \gamma_{i} a_{i j} \Delta q_{j}^{c s} \quad(\text { for } j=1,2, \ldots, S)
$$

If we stack over all commodities (i.e. $j=1,2, \ldots, S$ ), we obtain

$$
\Delta \mathbf{p}^{c p}=\Delta \mathbf{q}^{c p} \boldsymbol{\alpha} \mathbf{A}+\Delta \mathbf{q}^{t s} \boldsymbol{\beta} \mathbf{A}+\Delta \mathbf{q}^{c s} \boldsymbol{\gamma} \mathbf{A}
$$

where $\Delta \mathbf{p}^{\mathrm{cp}}, \Delta \mathbf{q}^{\mathrm{cp}}, \Delta \mathbf{q}^{\mathrm{ts}}$, and $\Delta \mathbf{q}^{\mathrm{cs}}$ each is a $1 \times \mathrm{S}$ vector; $\boldsymbol{\alpha}, \boldsymbol{\beta}$, and $\boldsymbol{\gamma}$ each is an $\mathrm{S} \times \mathrm{S}$ diagonal matrix; and $\mathrm{A}$ is an $\mathrm{S} \times \mathrm{S}$ matrix. If we substitute Eqs.(A5), (A6), and (A7) into Eq.(A11), we obtain

$$
\Delta \mathbf{p}^{c p}=\Delta \mathbf{p}^{c p} \boldsymbol{\alpha} \mathbf{A}+\Delta \mathbf{t}^{c p} \boldsymbol{\alpha} \mathbf{A}+\Delta \mathbf{p}^{w} \boldsymbol{\beta} \mathbf{A}+\Delta \mathbf{t}^{t s} \boldsymbol{\beta} \mathbf{A}+\Delta \mathbf{p}^{*} \boldsymbol{\gamma} \mathbf{A}
$$

If we collect terms, we obtain

$$
\Delta \mathbf{p}^{c p}=\Delta \mathbf{t}^{c p} \boldsymbol{\alpha} \mathbf{A} \mathbf{V}+\Delta \mathbf{p}^{w} \boldsymbol{\beta} \mathbf{A} \mathbf{V}+\Delta \mathbf{t}^{t s} \boldsymbol{\beta} \mathbf{A} \mathbf{V}+\Delta \mathbf{p}^{*} \boldsymbol{\gamma} \mathbf{A V}
$$

whereV $=(\mathbf{I}-\alpha \mathbf{A})^{-1}$ is an $S \times S$ matrix.

Eq.(A13) gives the vector of producer price changes in the cost-push sector. Nevertheless, we are interested in the vector of consumer price changes:

$$
\Delta \mathbf{q}=\Delta \mathbf{q}^{c p} \boldsymbol{\alpha}+\Delta \mathbf{q}^{t s} \boldsymbol{\beta}+\Delta \mathbf{q}^{c s} \boldsymbol{\gamma}
$$

In order to make this transition, we follow Andriamihaja and Vecchi (2008) by making the following assumptions. First, the only exogenous price changes are changes in the controlled sector; thus, $\Delta \mathbf{p}^{\mathrm{w}}=\Delta \mathbf{t}^{\mathrm{ts}}=\Delta \mathbf{t}^{\mathrm{cp}}=\Delta \mathbf{q}^{\mathrm{ts}}=0$. Second, all petroleum products are within the controlled sector whereas all other products are within the cost-push sector; hence, $\beta_{j}=0$ and $\alpha_{j}+\gamma_{j}=1$.

Given these assumptions, Eq.(A13) reduces to

$$
\Delta \mathbf{q}^{c p} \equiv \Delta \mathbf{p}^{c p}=\Delta \mathbf{p}^{*} \gamma \mathbf{A V}
$$

If we substitute Eq.(A15) into Eq.(A14), and noting that $\Delta \mathbf{q}^{\text {ts }}=0$ and $\Delta \mathbf{q}^{\text {cs }}=\Delta \mathbf{p}^{*}$, we obtain

$$
\Delta \mathbf{q}=\Delta \mathbf{p}^{*} \gamma \mathbf{A V \alpha}+\Delta \mathbf{p}^{*} \gamma=\Delta \mathbf{p}^{*}(\gamma \mathbf{A V} \boldsymbol{\alpha}+\gamma)
$$

Eq.(A16) gives the vector of consumer price changes $(\Delta \mathbf{q})$ due to changes in the prices of petroleum products $\left(\Delta \mathbf{p}^{*}\right)$. (Recall that $\Delta \mathbf{q}$ and $\Delta \mathbf{p}^{*}$ each is a $1 \times \mathrm{S}$ vector; $\mathbf{A}$ andV each is an $\mathrm{S} \times \mathrm{S}$ matrix; and $\boldsymbol{\alpha}$ and $\boldsymbol{\gamma}$ each is a $1 \times \mathrm{S}$ diagonal matrix.) Inasmuch as the data for $\mathbf{A}$ are readily available and the data for $\Delta \mathbf{p}^{*}$ were obtained earlier (i.e. $\Delta \mathbf{p}^{*}=$ $[50.14 \%, 50.14 \%, \ldots, 50.14 \%])$, it remains to obtain the data for $\alpha, \gamma$ and $\mathbf{V}$.

Since $\alpha_{j}$ and $\gamma_{j}$ denote the proportion of inputs needed to produce one unit of output in the $\mathrm{s}^{\text {th }}$ sector from the costpush and controlled (or petroleum) sectors, respectively, and $\alpha_{j}+\gamma_{j}=1$, then we need to identify the petroleum sectors in the I-O table. An examination of the table reveals that there are three petroleum sectors: crude oil and natural gas; petroleum refinery; and electricity and gas. For each of the 120 available sectors, $\gamma_{j}$ is derived by dividing the sum of the input coefficients in these petroleum sectors by the sum of the input coefficients in all sectors, and $\alpha_{j}$ is derived residually; i.e. $\alpha_{j}=1-\gamma_{j}$. Once $\alpha_{j}$ and $\gamma_{j}$ are obtained for the 120 sectors, we construct the matrix for $\alpha$ and $\gamma$ :

(A17) $\boldsymbol{\alpha}=\left[\begin{array}{cccc}\alpha_{1} & 0 & \ldots & 0 \\ 0 & \alpha_{2} & \ldots & 0 \\ \ldots \ldots \ldots \ldots \ldots \ldots \ldots . \\ 0 & 0 & \ldots & \alpha_{120}\end{array}\right], \boldsymbol{\gamma}=\left[\begin{array}{cccc}\gamma_{1} & 0 & \ldots & 0 \\ 0 & \gamma_{2} & \ldots & 0 \\ \ldots \ldots \ldots \ldots \ldots \ldots \ldots . . & \ldots \ldots \ldots \ldots\end{array}\right]$ 
From the formula $\mathbf{V}=(\mathbf{I}-\alpha \mathbf{A})^{-1}$, we have

$$
\begin{aligned}
& \text { (A18) } \mathbf{V}=\left(\left[\begin{array}{cccc}
1 & 0 & \ldots & 0 \\
0 & 1 & \ldots & 0 \\
\ldots \ldots \ldots \ldots \ldots \ldots . \\
0 & 0 & \ldots & 1
\end{array}\right]-\left[\begin{array}{llll}
\alpha_{1} & 0 & \ldots & 0 \\
0 & \alpha_{2} & \ldots & 0 \\
\ldots \ldots \ldots \ldots \ldots \ldots \ldots \\
0 & 0 & \ldots & \alpha_{120}
\end{array}\right]\left[\begin{array}{llll}
a_{11} & a_{12} & \ldots & a_{1,120} \\
a_{21} & a_{22} & \ldots & a_{2,120} \\
\ldots \ldots \ldots \ldots \ldots \ldots \ldots \ldots \\
a_{S 1} & a_{S 2} & \ldots & a_{120,120}
\end{array}\right]\right)^{-1}
\end{aligned}
$$

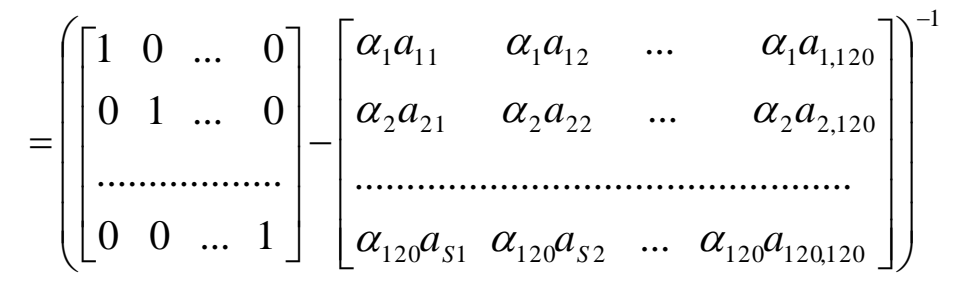

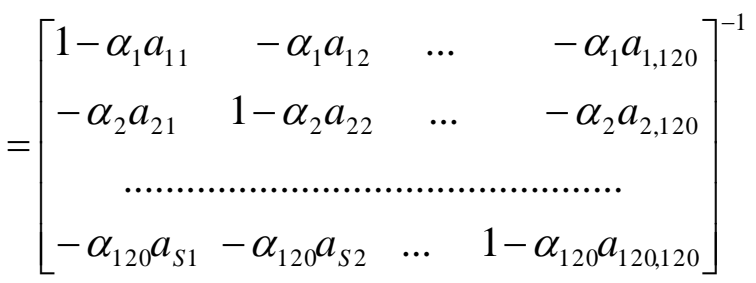

Once all of these data are obtained, $\Delta \mathbf{q}$, which is a $1 \times 120$ vector of the consumer prices of goods and services, can be calculated based on Eq.(A16). 